\title{
The Effect of Chromium Additions on the Microstructure and Some Mechanical Properties of Delta Steel Company Nodular Cast Iron
}

\author{
S.O Jimoh ${ }^{1}$, N. N.Ehigiamusoe ${ }^{2}$ \\ Department of Industrial and Production Engineering, Ambrose Alli University Ekpoma, Edo State ${ }^{1,2}$
}

\begin{abstract}
The effects of chromium additions on the microstructure and some mechanical properties of nodular cast iron have been determined. The nodular cast iron samples containing from $0.6 \%$ to $2.6 \%$ chromium were produced at Delta steel company. The mechanical properties studied include: Tensile strength, hardness and percentage elongation. The results indicate that the tensile strength and hardness of the samples increased with percentage chromium additions from $449 \mathrm{~N} / \mathrm{mm}^{2}$ at $0 \%$ chromium to $544 \mathrm{~N} / \mathrm{mm}^{2}$ at $2.6 \%$ chromium and from $195 \mathrm{BHN}$ at $0 \%$ chromium to $323 \mathrm{BHN}$ at $2.6 \%$ chromium. However, the percentage elongation of the nodular cast iron sample decreased with increasing percentage chromium additions from $9 \%$ at $0 \%$ chromium to $2 \%$ chromium additions. The microstructure revealed an increase in degree of pearlite phase together with some precipitates of Chromium carbide phase as the chromium level increased.
\end{abstract}

Keywords: Chromium, Nodular Cast Iron, Ferrous Metals.

\section{INTRODUCTION}

For a long time, chromium has been added to cast irons, particularly for applications requiring enhanced compared properties with those obtainable from ordinary white, grey and nodular cast iron compositions. However, a distinction is frequently made between the small additions of chromium cast iron having characteristic properties and microstructures of their own.

At the low end of the chromium addition, small additions of up to about 1.5 are added to grey cast irons for solid solution hardening of the pearlite and to prevent distortion and 'growth' when utilized at high temperatures, (1). In this case a simultaneous addition of nickel or silicon is frequently necessary, especially for thin section castings in order to counteract the inevitable 'whitening' effect of chromium. Small quantities of chromium are also added to centrifugally cast piston rings and cylinder liners, to prevent where massive carbide in a pearlitic matrix is required for optimum service properties, (1 and 2).

Higher additions in the order of 2 to 2.5 percent of chromium are sometimes made to white irons for roll making and other heavy section castings to maintain whiteness; (3, 4 and 6). Similarly, in martensitic white cast iron, chromium is used to counteract the 'greyness' that would otherwise result from nickel addition required to form the martensitic matrix to the alloy; (7).

The use of chromium as alloying element for nodular cast iron is not common due to the fact chromium causes chilling effect on iron and this could adversely affect some of the properties of nodular cast iron. Hence, care must be taken if used in order to control the chilling effect. In Iron-carbon- chromium system, different types of $\mathrm{Fe}-\mathrm{C}-\mathrm{Cr}$ carbides are formed in chromium alloyed cast irons and steels. The hardness of these carbides increases with the chromium content. The objective of the present study is to investigate the influence of small additions of chromium on the microstructure and the mechanical properties of nodular cast iron produced locally.

\section{EXPERIMENTAL PROCEDURES}

\section{MATERIALS}

The materials used for the study was chromium alloyed nodular cast iron which was produced at Delta Steel Company Limited in the form of rods measuring $400 \mathrm{~mm}$ by $600 \mathrm{~mm}$ length. The chemical composition of the different nodular cast iron grades produced are given in table 1(Aboh, 2002). 
International Journal of Innovative Research in

Electrical, Electronics, Instrumentation and Control Engineering

Vol. 8, Issue 9, September 2020

DOI 10.17148/IJIREEICE.2020.8902

All tensile tests were performed on a Hounsfield tensometer-testing machine. The Brinell hardness testing machine was used for hardness measurement of the chromium nodular cast iron samples. A metallurgical microscope with an in-built camera was used to examine and photographically record the microstructure of the various nodular cast irons samples. A metallurgical microscope with an in-built camera was used to examine and photographically record the microstructure of the various nodular cast irons samples.

\section{METHODS}

Standard tensile test specimen of $5 \mathrm{~mm}$ diameter and $20 \mathrm{~mm}$ long were machined from a 40mm diameter and $600 \mathrm{~mm}$ long chromium alloyed nodular cast iron rod. The length of the specimen was chosen to be four times its diameter, in order to conform to the standard size. In all, twelve chromium alloyed nodular cast iron specimens were machined out for use during the test.

The tensile tests, metallurgical examinations and hardness measurement of the chromium alloyed nodular cast iron specimens were used to assess the effect of chromium on the microstructure and some mechanical properties of nodular cast iron under determination.

The tensile tests were carried out on a Hounsfield tensometer using the machined cylindrical tensile test specimens of $5 \mathrm{~mm}$ in diameter and a gauge length of $20 \mathrm{~mm}$. Two samples were tested for each grade of the nodular iron. The maximum strength and percentage elongation were determined. The result is shown in figure 1 and 2 and table 2 .

Before subjecting the specimens to hardness test, they were mounted on fused Bakelite powder for easy handling surface preparation was carried out by grinding to obtain a smooth surface.

Micro-structural examination of specimens cut from the fractured chromium alloyed nodular cast iron was carried out. Each specimen was carefully ground and polished. The surface of the polished specimen was etched in 5 percent Nital by swabbing the surface with cotton wool soaked in the etchant. The microstructural examination of the etched surface of the specimen was made under optical metallurgical microscope with an in-built camera through which the resulting microstructures were all photographically recorded. The micrographs are shown in plates 1-6.

\section{RESULTS}

Table 1 shows the chemical composition of the nodular cast iron used in this investigation. The various microstructures resulting from the additions of chromium to nodular cast iron are shown in plates 1-6. The effect of chromium additions on some mechanical properties of the nodular cast iron produced at Delta Steel Company Table 2 and the graphs presented in figures 1-3 show the variation of these mechanical properties with chromium additions.

Table 1: Chemical Composition of Nodular Cast Iron Produced

\begin{tabular}{|l|l|l|l|l|l|}
\hline \% Cr & \% Si & \%Mn & \%S & \% P & Cr \\
\hline 3.00 & 2.00 & 0.46 & 0.031 & 0.13 & 0.0 \\
3.25 & 2.03 & 0.67 & 0.031 & 0.02 & 0.6 \\
3.15 & 2.20 & 0.44 & 0.020 & 0.38 & 1.1 \\
3.31 & 2.10 & 0.41 & 0.070 & 0.39 & 1.6 \\
3.42 & 2.44 & 0.56 & 0.060 & 0.42 & 2.1 \\
3.42 & 2.44 & 0.56 & 0.060 & 0.42 & 2.6 \\
\hline
\end{tabular}

MICROGRAPHS OF NODULAR CAST IRONS WITH CHROMIUM ADDITIONS

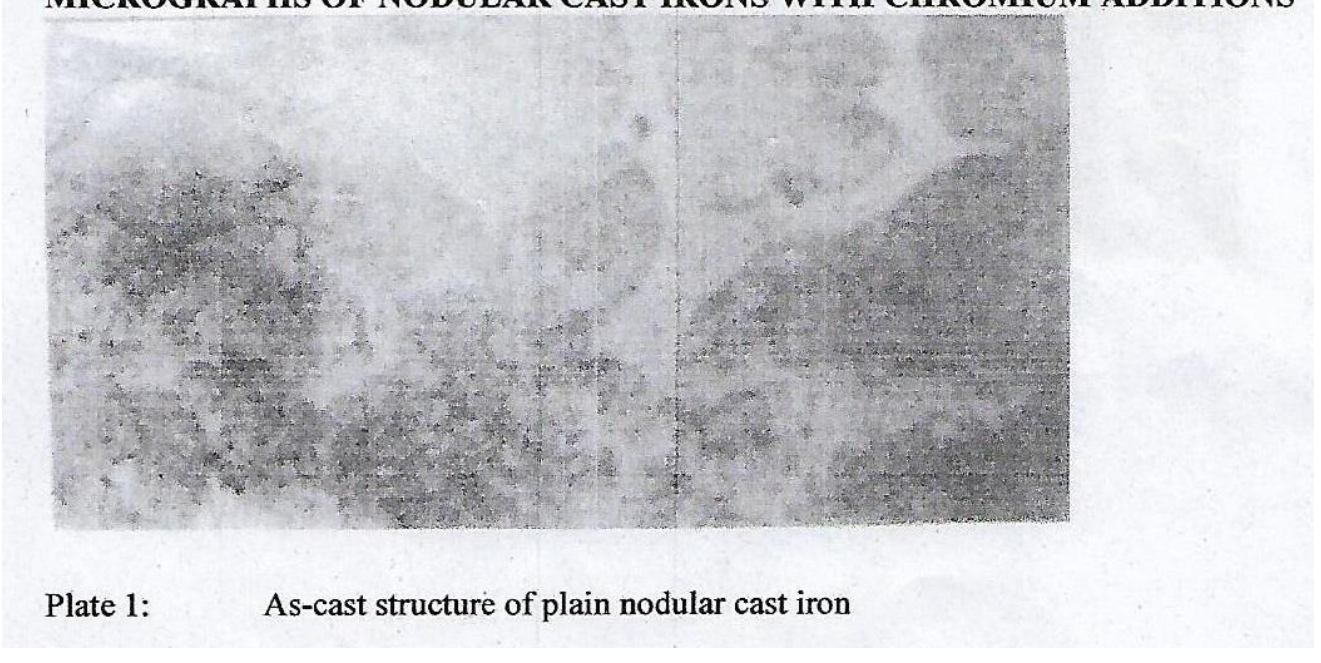


International Journal of Innovative Research in Electrical, Electronics, Instrumentation and Control Engineering

Vol. 8, Issue 9, September 2020

DOI 10.17148/IJIREEICE.2020.8902

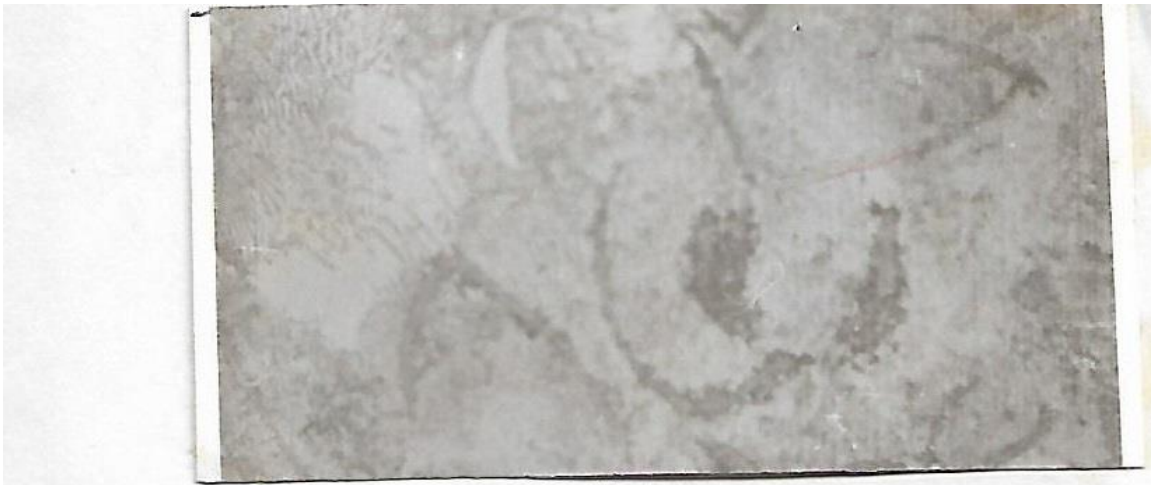

Plate 2: As-cast structure of $0.6 \% \mathrm{Cr}$ nodular cast iron

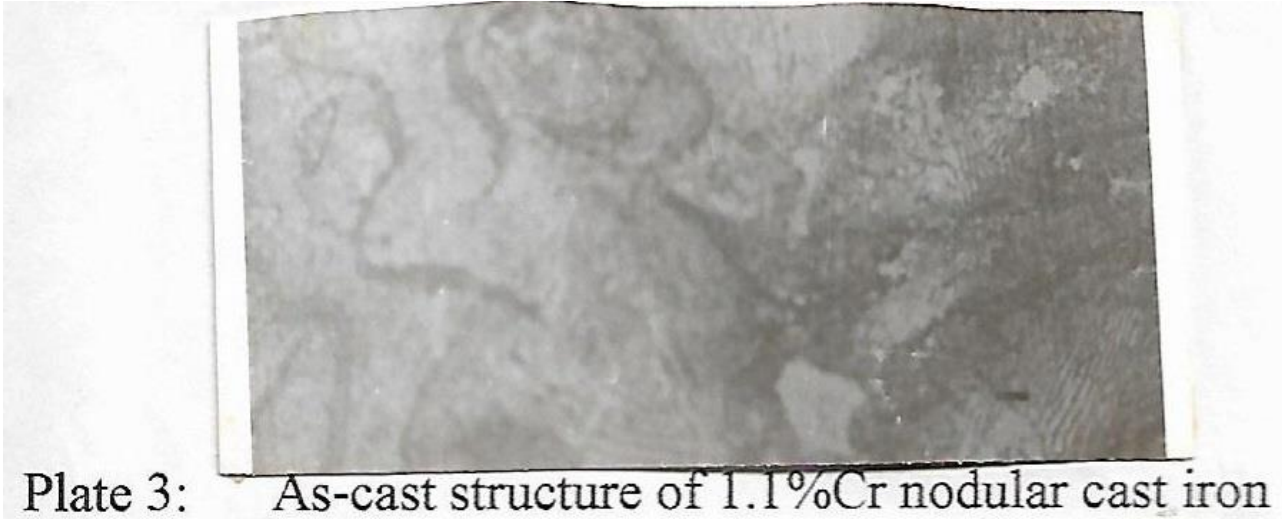

Plate 4: As-cast structure of $1.6 \% \mathrm{Cr}$ nodular cast iron

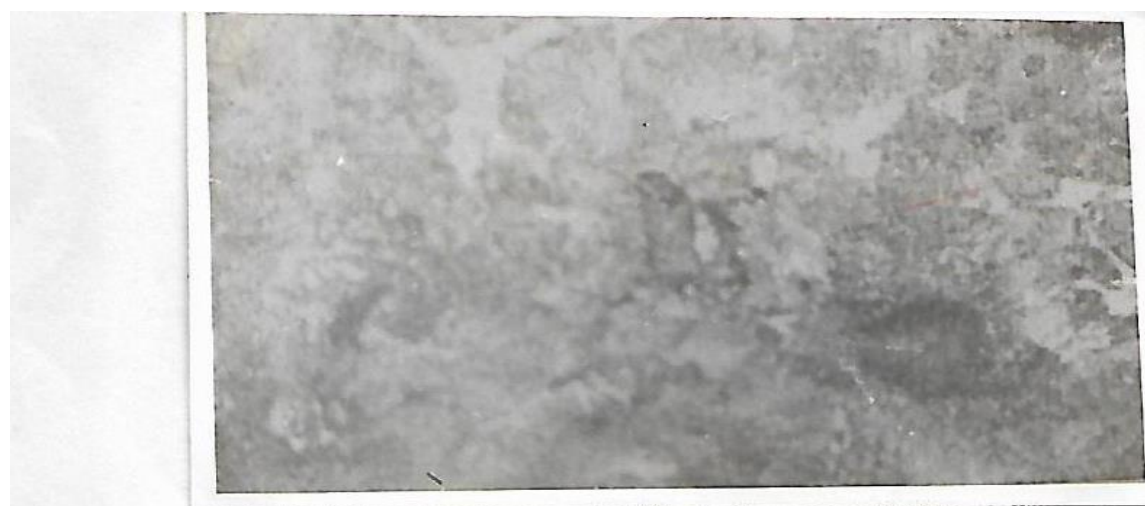

Plate 5: As-cast structure of $2.1 \% \mathrm{Cr}$ nodular cast iron 
International Journal of Innovative Research in Electrical, Electronics, Instrumentation and Control Engineering

Vol. 8, Issue 9, September 2020

DOI 10.17148/IJIREEICE.2020.8902

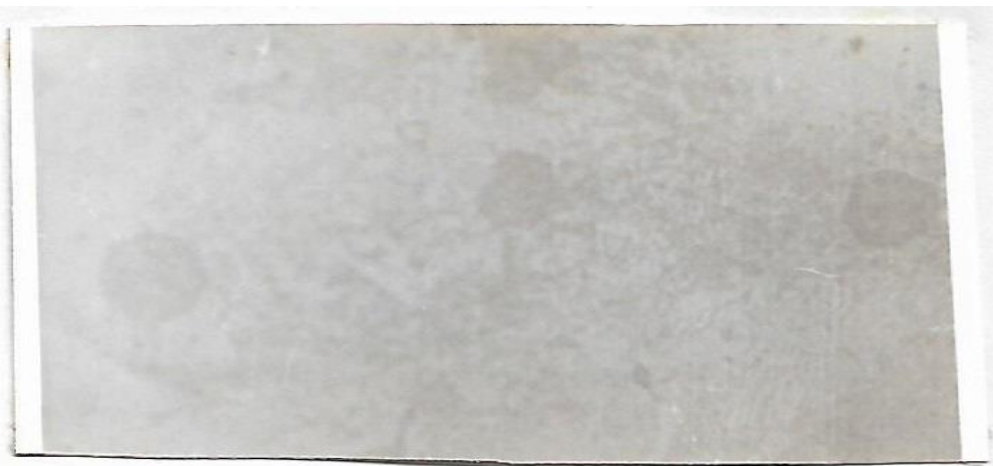

Plate 6: As-cast structure of $2.6 \% \mathrm{Cr}$ nodular cast iron

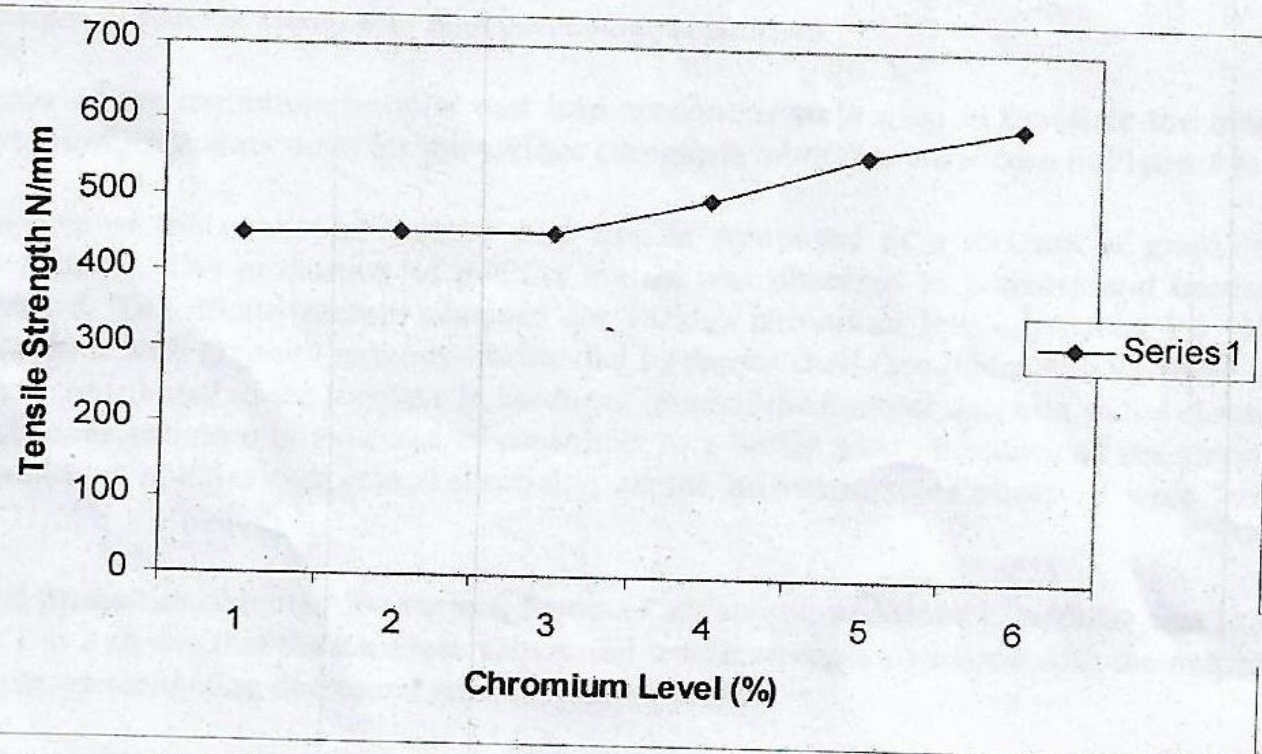

Figure 1: Variation of tensile strength with percentage chromium

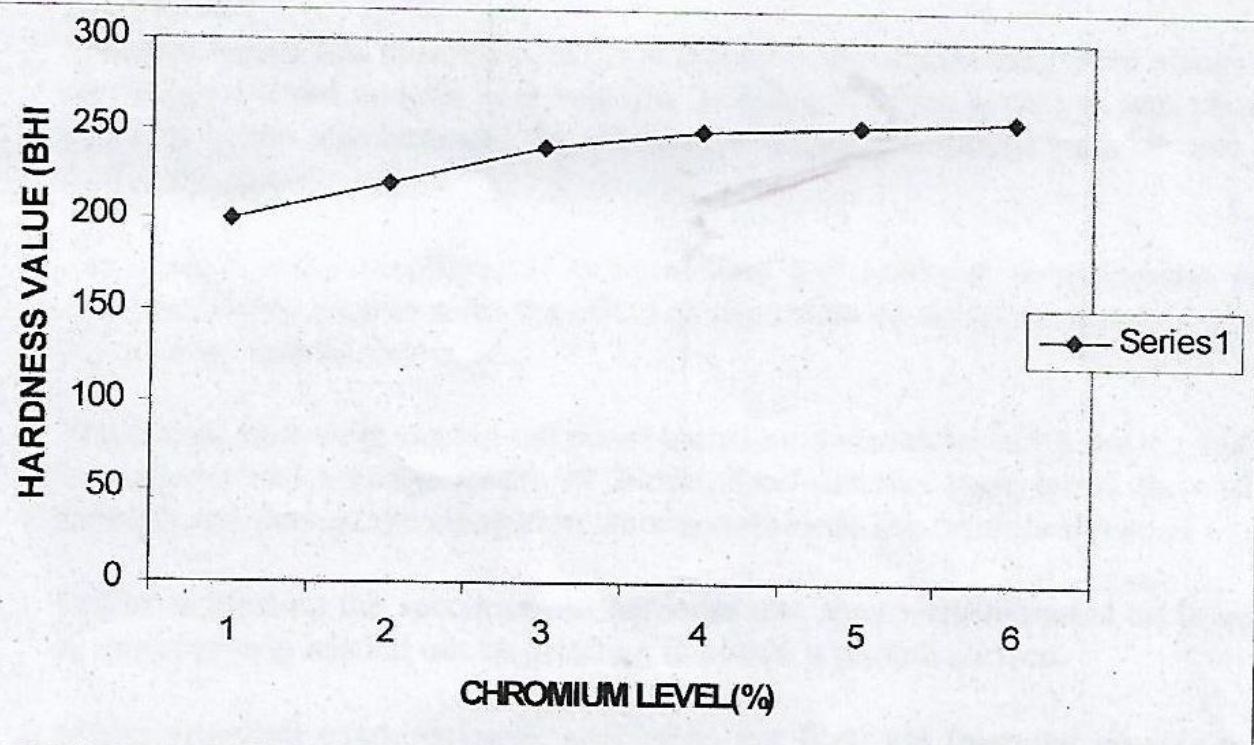

Figure 2: Variation of hardness value with percentage chromium 
International Journal of Innovative Research in Electrical, Electronics, Instrumentation and Control Engineering

Vol. 8, Issue 9, September 2020

DOI 10.17148/IJIREEICE.2020.8902

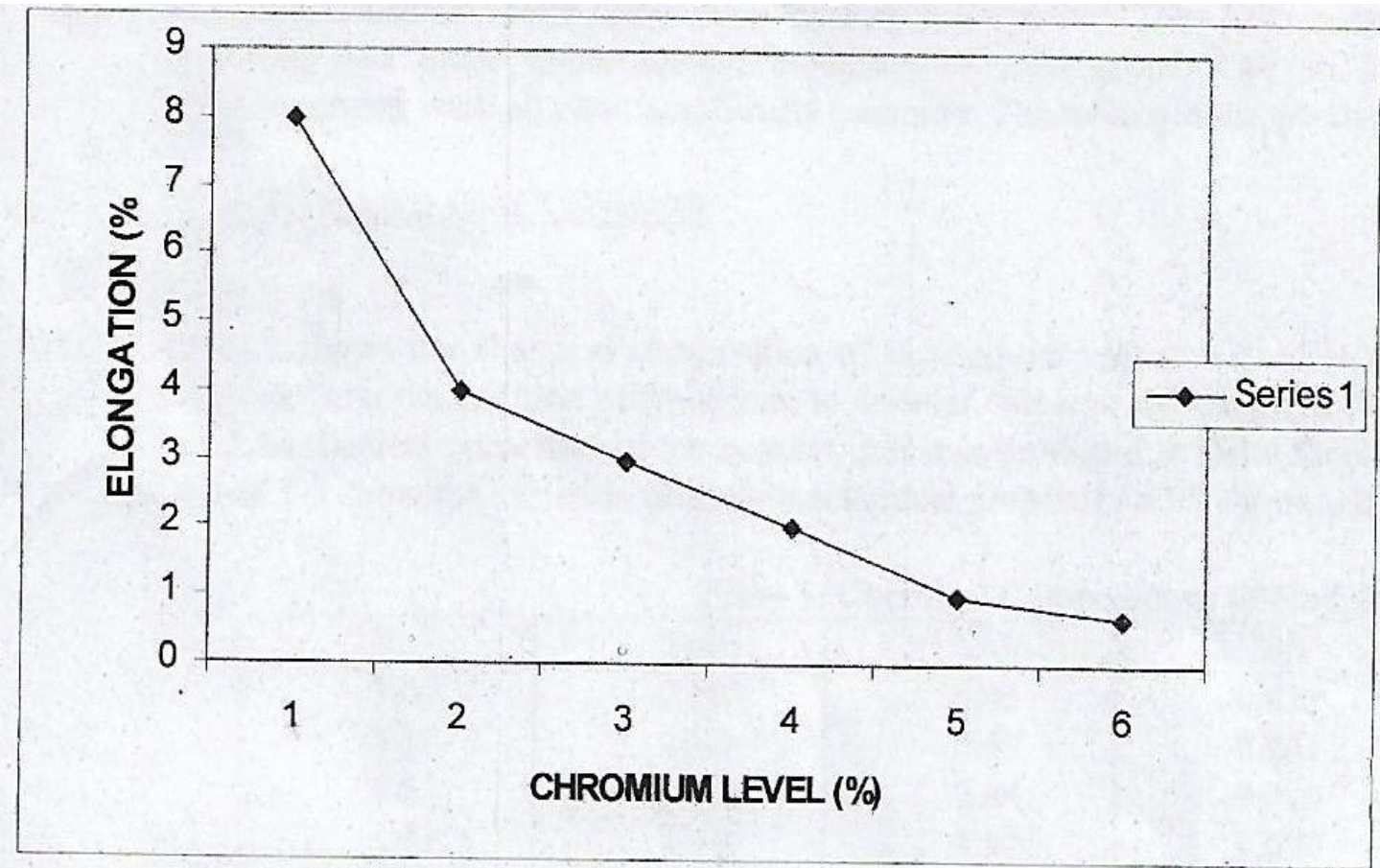

Figure 3: Variation of percent elongation with percentage chromium

\section{DISCUSSION}

The micrographs of the chromium nodular cast iron specimens were used to correlate the mechanical properties values obtained. The typical microstructures for the various chromium additions are shown in plates 1 to 6 .

The microstructure of the unalloyed nodular cast iron is composed of a mixture of graphite and pearlite mixture as expected (see plate 1). The proportion of pearlite matrix was observed to increase and become finer as the chromium additions increased. The microstructure obtained for various chromium levels between $1.6-2.6 \%$ shows a highly fine pearlite phase matrix with graphite nodules surrounded by ferrite shell (see plates 4 to 6 ), these uniformly distributed hard pearlite matrices contributed to the increase in hardness value of the nodular cast iron as the chromium addition increases. The pearlite matrices structure is expected to contribute to a better wear resistance of the chromium nodular cast iron as compare to unalloyed nodular cast iron. Essentially, all the microstructures observed were ferrite, pearlite and graphite nodules. The mechanical properties obtained for various levels of chromium additions to nodular cast iron summarized in table 2 and in figure 1 to 3 shows that the hardness values and tensile strength increased with the percentage chromium additions while the percentage elongation decreased with chromium levels.

The increase in pearlite matrix structure obtained as the percentage chromium increased resulted in the increase in the hardness values of he nodular cast iron specimen and therefore better wears resistance. However, there is a general reduction in ductility of these nodular cast iron grades with chromium additions as reflected in the percentage elongation values as shown in figure 3. It is noteworthy to observe that higher tensile strength values were developed as the chromium level increased to 2.6 percent and probably this trend may continue even before this level.

From this study, the high hardness values obtained in these nodular cast iron specimens as the percentage chromium addition increased could, therefore, be attributed to the carbide formation and stability characteristics of chromium as alloying element in ferrous metals.

\section{CONCLUSION}

The influence of chromium additions on the microstructure and mechanical properties of nodular cast iron produced from Delta Steel Company Nigeria has been quantitatively assessed using hardness values, tensile strength and percent elongation.

From experimental result obtained, it can be seen that; the mechanical properties of the nodular cast iron can be enhanced by the addition of chromium up to 2.6 percent level without embrittling the nodular cast iron. The improved mechanical properties (tensile strength and hardness) are due to the presence of chromium carbide phase that is formed in the microstructure of the cast iron. Hence, this low level of chromium addition develops a material with better wear resistance. 
International Journal of Innovative Research in Electrical, Electronics, Instrumentation and Control Engineering

Vol. 8, Issue 9, September 2020

DOI 10.17148/IJIREEICE.2020.8902

\section{ACKNOWLEDGMENT}

The assistance of Delta Steel Company of Nigeria, Delta State, Nigeria where the research materials were produced is greatly acknowledged. The authors wish to appreciate the assistance of the Dorman Engineering Ltd Lagos, during the production if photomicrographs.

\section{REFERENCES}

[1]. Angus, H.T (1976) “cast iron: Physical and Engineering Properties”. Butterworths and Co. Ltd; London 2 ${ }^{\text {nd }}$ edition, pp. 12-21, 157-160, 130-329

[2]. Baily, S.B (1954) "Nodular Cast iron- its present position and future prospect as an engineering materials, with special reference to its suitability for crankshafts", Proc Inst of Mech Engrs Vol. 168, pp. 648-678

[3]. Charles F. Wanton(1971) "Metallurgy; Theory and Practice", American Technical Society, Chicago.

[4]. William F. Smith (1990) "Principles of Materials Science and Engineering" $2^{\text {nd }}$ ed,. Mc Graw-Hill Publishing Co. New York, pp.535-544.

[5]. Charles F. Wanton (1971); Grey and Ductile Iron Casting Handbook; Grey and Ductile Iron Founders Society Inc., Cleveland

[6]. Roy Elliot (1988) “Cast Iron Technology" Butterworth and Co. Ltd, London, pp. 130

[7]. Morrogh, H. (1964): British Foundryman, Vol.57, pp.297

[8]. Cast Iron for abrasion resisting applications" Conference Paper, Institute of British Foundryman,pp.34-41.

\section{APPENDIX}

Table 2: mechanical properties of As- cast Chromium Alloyed Nodular Cast Iron

\begin{tabular}{|l|l|l|l|}
\hline$\%$ cr & Tensile Strength $\left(\mathbf{N} / \mathbf{m m}^{2}\right)$ & Hardness $(\mathrm{BHN})$ & Elongation $(\%)$ \\
\hline 2.0 & 449 & 195 & $\mathbf{8 . 0}$ \\
0.6 & 459 & 205 & 3.5 \\
1.1 & 480 & 214 & 3.0 \\
1.6 & 500 & 218 & 2.5 \\
2.1 & 520 & 227 & 2.0 \\
2.6 & 543 & 232 & 1.0 \\
\hline
\end{tabular}

